\title{
STALKING: CRIMINALIZAÇÃO NECESSÁRIA SOB A INDUBITÁVEL AFRONTA AO DIREITO FUNDAMENTAL À VIDA PRIVADA
}

\section{STALKING: CRIMINALIZATION REQUIRED UNDER THE INDUBUTABLE AFFRONT RIGHT TO LIFE PRIVATE}

\author{
Jessika Milena Silva Machado ${ }^{1}$ \\ Patrícia Ribeiro Mombach ${ }^{2}$
}

Resumo: $\mathrm{O}$ direito fundamental à vida privada consubstancia-se importante ao próprio desenvolvimento humano. Contudo, ao longo do tempo vem sofrendo ameaças que atualmente ganharam intensidade e se mostram mais comuns e devastadoras, face aos avanços tecnológicos. Nesse quadro de violação, existe a prática do stalking, ação na qual o agente persegue sua vítima, de forma reiterada ou continuada, causando-lhe medo e atentando contra sua integridade psicológica ou física, além de invadir sua privacidade. Todavia, esta perseguição não é crime no Brasil, apenas pune-se como contravenção penal. Necessária, no entanto, sua criminalização.

Palavras-chave: Vida privada. Stal- king. Perseguição. Criminalização.

Abstract: The fundamental right to privacy embodied is important for human development itself, but has been threatened a long time, which is currently intensified, leaving most common and devastating, due to technological advances. This breach framework, there is the practice of stalking where the agent pursues his victim repeatedly or continuously, causing him fear and impairing their psychological or physical integrity. But this persecution is not a crime in Brazil, only punishes with misdemeanor. Necessary, however, its criminalization .

Keywords: Life. Stalking. Persecution. Criminalization.

1 Residente judicial da Terceira Câmara de Direito Público do Tribunal de Justiça do Estado de Santa Catarina, lotada no gabinete do Desembargador César Augusto Mimoso Ruiz Abreu. Pós-graduada em Direito Público e pós-graduanda em Direito Aplicado, ambas pela FURB, e em Direito Ambiental pela Universidade do Sul de Santa Catarina (Unisul).E-mail: jessikamsm@gmail.com

2 Professora da Unisul. Advogada criminalista. Especialista e mestre em Ciências Criminais pela Pontifícia Universidade do Rio Grande do Sul (PUC/RS). E-mail: patriciamombach@yahoo.com.br 


\section{INTRODUÇÃO}

O presente artigo tem como objetivo estudar a prática do stalking, analisando o direito fundamental à vida privada, sendo de primeira geração, tutelado pela Constituição da República Federativa do Brasil, de 1988, apontando, no segundo capítulo, a importância deste para o desenvolvimento da pessoa humana.

Já em terceiro plano, traz-se a baila as novas formas de relacionamento humano, em razão dos avanços tecnológicos, sendo que ocorrem por meio da internet (redes sociais) e aparelhos eletroeletrônicos (celulares e tabletes). Ainda, mostra-se que esses novos meios de relacionamento trazem consigo violações ao direito supracitado, o que resta temerário.

Em razão desses quadros de transgressões, surge o estudo do stalking, cujo quarto capítulo traz seu conceito e a evidente afronta da prática de perseguição à vida privada. Sendo assim, discorre-se sobre a necessidade imprescindível da criminalização do stalking.

\section{CONCEITO E APONTAMENTOS DO DIREITO CONSTITUCIONAL FUNDAMENTAL À VIDA PRIVADA}

Importa inicialmente salientar que todas as pessoas são titulares de direitos fundamentais, e que a qualidade de ser humano é condição, sem mais nada exigir, para a titularidade desses direitos.

Oportunamente menciona-se que os direitos fundamentais são resultados do processo de constitucionalização dos direitos humanos, portanto inerentes, ainda que não desejados, a todos. Nesse passo, constituem-se como os objetivos previstos em determinada ordem jurídica, devendo ser respeitados por todos, tal qual Estado, particulares e pessoas jurídicas. 
Fernandes (2015, p. 311-312) observa:

[...] os direitos fundamentais não podem ser tomados como verdades morais dadas previamente, mas como elementos em constante processo de (re)construção, haja vista que sua justificação e normatividade decorrem de uma Constituição positiva, igualmente mutável.

Sendo os direitos fundamentais coronário dos direitos humanos, pode-se dizer que ao longo do tempo, face às modificações sociais e jurídicas, surgiram novos daqueles direitos, enquanto outros já longevos sofreram alterações. Evidenciam tal transformação as gerações dos direitos fundamentais descritas por Mendes, Coelho e Branco(2010, p. 309-310), que discorrem:

A primeira delas abrange os direitos referidos nas Revoluções americana e francesa. São os primeiros a serem positivados, daí serem ditos de primeira geração. Pretendia-se, sobretudo, fixar uma esfera de autonomia pessoal refratária às expansões do Poder. Daí esses direitos traduzirem-se em postulados de abstenção dos governantes, criando obrigações de não fazer, de não intervir sobre os aspectos da vida pessoal de cada indivíduo. São considerados indispensáveis a todos os homens, ostentando, pois pretensão universalista. [...] O paradigma de titular desses direitos é o homem individualmente considerado. [...] Os direitos de segunda geração são chamados de direitos sociais, não porque sejam direitos de coletividade, mas por se ligarem a reivindicações de justiça social-na maior parte dos casos, esses direitos têm por titulares indivíduos singularizados. Já os direitos chamados de terceira geração peculiarizam-se pela titularidade difusa ou coletiva, uma vez que são concebidos para a proteção não do homem isoladamente, mas de coletividade, de grupo. Tem-se, aqui, o direito à paz, ao desenvolvimento, à qualidade do meio ambiente, à conservação do patrimônio histórico e cultural.

Ainda acerca dos direitos de primeira geração, atributos da pessoa humana, Ardenghi(2012, p. 231) menciona que"entre esses direitos situam-se: as liberdades físicas, as liberdades de 
expressão, as liberdades de consciência, as liberdades de propriedade privada, os direitos da pessoa acusada e as garantias dos direitos".

Realizadas breves considerações sobre os direitos fundamentais, passa-se à análise de um deles, qual seja, o direito fundamental à vida privada, o qual, como acima exposto, surgiu na primeira geração.

No âmbito internacional, o direito à privacidade garantiu proteção no ano de 1948, por meio da Declaração Americana dos Direitos e Deveres do Homem e da Declaração Universal dos Direitos Humanos.

Já no Brasil, a Constituição da República Federativa, de 1988, foi o primeiro diploma legal que tratou do tema, especificadamente no art. $5^{\circ}$, inciso X, prevendo: "São invioláveis a intimidade, a vida privada, a honra e a imagem das pessoas, assegurado o direito a indenização pelo dano material ou moral decorrente de sua violação." (BRASIL, 1998).

Interessa dispor que o direito à vida privada, quando visto sob o prisma do Direito Constitucional-enquanto direito fundamental, no qual paira conflitos de interesse entre o particular e o Estado - ou sob a ótica do direito da personalidade, constatando-se, por meiodo Direito Civil, na proteção a individualidade, possui o mesmo objetivo, qual seja, salvaguardar a pessoa humana em seu íntimo.

Antes de conceituar o direito à vida privada, é importante mencionar que este muito se confunde com o direito à intimidade, ao passo que ambos tratam do foro íntimo do ser humano. James Eduardo Oliveira citado por Lobo (2013, p. 107-108) diferencia-os:

O direito à intimidade diz respeito a fatos, situações e acontecimentos que a pessoa deseja ver sob seu domínio exclusivo, sem compartilhar com qualquer outra. É a parte inte- 
rior da história de vida de cada um, que o singulariza, e que deve ser mantida sob reserva. Estão cobertos pelo manto tutelar da intimidade os dados e documentos cuja revelação possam trazer constrangimentos e prejuízos à reputação da pessoa, quer estejam na moradia, no automóvel, no clube, nos arquivos pessoais, na bagagem, no computador, no ambiente de trabalho. O conceito de intimidade varia de pessoa para pessoa, mas acima de tudo depende da cultura de onde emergiu sua formação, em cada época e nos diferentes lugares onde desenvolva seu projeto existencial. $\mathrm{O}$ direito à vida privada diz respeito ao ambiente familiar, cuja lesão resvala nos outros membros do grupo. O gosto pessoal, a intimidade do lar, as amizades, as preferências artísticas, literárias, sociais, gastronômicas, sexuais, as doenças porventura existentes, medicamentos tomados, lugares frequentados, as pessoas com quem se conversa e sai, até o lixo produzido, interessam exclusivamente a cada indivíduo, devendo ficar fora da curiosidade, intromissão ou interferência de quem quer que seja.

Ou seja, a vida privada diz respeito aos elementos que formam a vida de uma pessoa e que não são de conhecimento público. Portanto, dentro da esfera da vida privada tende-se à intimidade.

Sendo foco do presente artigo o direito fundamental à vida privada, Ferrari citado por Ferraz (2011, p. 610), atribui-lhe conceito ao aduzir que é:

[...] um direito subjetivo fundamental, cujo titular é toda pessoa, física ou jurídica, brasileira ou estrangeira, residente ou em trânsito no País, cujo conteúdo é a faculdade de constranger os outros ao respeito e de resistir à violação do que lhe é próprio, isto é, das situações vitais que, por só a ele lhe dizerem respeito, deseja manter para si, ao abrigo de sua única e discricionária decisão, e cujo objeto é a integridade moral do titular.

Ao discorrer sobre o tema Bulos (2012, p. 137) menciona que, ao se tratar de "termo derivado da expressão ampla privacidade, pretende-se designar o campo de intimidades do 
indivíduo, o repositório de suas particularidades de foro moral e interior, o direito de viver sua própria vida, sem interferências alheias".

Em síntese, é pela tutela do direito à privacidade que "[...] se deve limitar a penetração externa no âmbito em que cada um quer manter exclusivamente para si”, entendendo-se, dessa forma, como "[...] o direito de excluir razoavelmente da informação alheia, fatos e danos pertinentes ao sujeito". (ARDENGHI, 2012, p. 248).

Cumpre dizer que o direito à vida privada é mais do que fundamental, já que é necessário ao desenvolvimento do ser humano. Pois:

Vale, então, destacar que uma certa dose de reserva e de
recolhimento é de importância fundamental para o desen-
volvimento saudável da personalidade, pois o desenvolvi-
mento do sentimento de família e de infância só se desen-
volveu nos séculos XVI e XVII, quando a família buscou,
no restrito círculo familiar, motivos de vida em comum, e
no cotidiano do lar, criou espaços privados de convivência,
adquirindo consciência de espaço privado e público, e gos-
to pela vida isolada. (ARDENGHI, 2012, p. 238).

Em suma, o direito à vida privada tutela aquelas manifestações da esfera íntima da pessoa humana, constituindo-se em um agrupamento de fatores como: modo de viver, hábitos, relações familiares, segredos, particularidades, planos, sonhos, pensamentos, dentre outros. Por conseguinte, reflete ele a dignidade da pessoa humana, onde todos os indivíduos têm o poder de escolha, face à liberdade, e podem conduzir suas vidas conforme desejarem, longe dos olhos, apontamentos e curiosidades alheias.

Importa mencionar que o direito fundamental aqui em comento não é absoluto, sendo "[...] inviolável enquanto permanecer na esfera pessoal do indivíduo, sem refletir em relação a outros" (FERREIRA FILHO, 2011, p. 351). Porquanto, me- 
rece absoluta tutela quando se tratar unicamente das questões pessoais da pessoa humana, porém, ultrapassando o limite tênue da infringência do direito de outro, é relativizado. É o que ocorre, por exemplo, com a interceptação de comunicações telefônicas, regulada pela Lei $n^{\circ} 9.296 / 96$. Indiscutível que a interceptação de uma conversa telefônica fere a privacidade e intimidade do indivíduo, no entanto, quando praticada nos casos e na forma prevista na citada lei, ela é admitida.

Outra consideração que merece ser feita é referente à restrição ao direito de privacidade a partir do consentimento da própria pessoa, ao passo que este, enquanto direito fundamental, pode sofrer autolimitação. Ou seja, o indivíduo pode falar de sua vida privada em uma entrevista, por exemplo, limitando o conteúdo da exposição; ou ainda a pessoa pode, tacitamente, consentir. Um exemplo seria quando estiver caminhando pelas vias públicas, ficando exposta para que outras pessoas a vejam, podendo tirar fotos ou fazer filmagens. Porém, "nesse contexto de ponderação entre o interesse público na notícia e a privacidade do indivíduo, compreende-se que pessoas públicas ou envolvidas em assuntos públicos detenham menor pretensão de retraimento da mídia". (MENDES; COELHO; BRANCO, 2010, p. 475).

Diante do exposto, pode-se aduzir que o direito à vida privada, apesar de ser relativizado em determinadas situações, consubstancia-se em um direito fundamental e visa proteger o indivíduo, para que este não seja foco da observação de terceiros, bem como para que não tenha suas relações pessoais e informações expostas também a estes.

\section{HODIERNAS FORMAS DE RELACIONAMENTO HUMANO}

Indubitável que o direito à vida privada sofre constante 
afronta, sendo alvo de assédios desmedidos. O suposto marco histórico que aponta transgressão e transposição afrontosa à vida privada, foi posterior à Revolução Industrial, sendo que esta trouxe consigo mudanças devastadoras para as relações humanas, pertinentes ao crescimento desordenado das relações de consumo e aliada às tecnologias e inovações, arcabouços que hoje são ferramentas dinamizadoras, porém também destrutivas.

Há relato de que "[...] a proteção da vida privada foi judicialmente acolhida, pela primeira vez, em França, no julgado do Tribunal Civil do Sena, de 16 de junho de 1858". (COSTA JÚNIOR, 2004, p. 14).

Acerca do surgimento do direito fundamental à vida privada:

Pode-se dizer que ele somente veio a ser apercebido como uma das projeções da dignidade da pessoa humana quando o desenvolvimento dos meios de comunicação-primeiro da imprensa-vieram a ameaçar a privacidade individual.

Com efeito, o desenvolvimento da imprensa e particularmente dos meios audiovisuais de comunicação de massa, por um lado, da informática, por outro, veio pôr em grave risco o direito de cada um não ver exposta a sua vida privada, e mais, a sua vida íntima à discrição alheia. Inclusive a do Estado. (FERREIRA FILHO, 2011, p. 347).

Impiedoso dizer que a era tecnológica, abarcada por seu próprio dinamismo, trouxe consigo vantagens e desvantagens no que diz respeito ao relacionamento humano e à privacidade. O exibicionismo também fora asseverado ao longo do tempo.

Costa Júnior (2004, p. 18) expressa categoricamente:

O processo de corrosão das fronteiras da intimidade, o devassamento da vida privada, tornou-se mais agudo e inquietante com o advento da era tecnológica. As conquistas desta era destinar-se-iam em tese a enriquecer a personalidade, ampliando-lhe a capacidade de domínio sobre a natureza, aprofundando o conhecimento, multiplicando e disseminando a riqueza, revendo e promovendo novos rumos 
de acesso ao conforto.

O ser humano passou por inúmeras transformações. Partiu-se do ponto de respeito à vida privada e se chegou ao ponto de ceder, embora muitas vezes inconsciente, a própria vida, permitindo que os meios de comunicação e divulgação contemporâneos tomem conta de todas as particularidades mais íntimas da pessoa. Tão raramente hoje nos deparamos com pessoas que não se comunicam por meio dos aparelhos celulares, não utilizam a internet para entrar nas redes sociais e postar fotos de onde estão ou estiveram. Cada vez mais há procura por esses mecanismos de interlocução.

Assevera Gonçalves (2011, p. 331) que:

[...] em dias de superexposição o que realmente importa é a popularidade, a notoriedade e a atenção conquistada por um novo público, mesmo que não se conheça a totalidade das pessoas que integram a rede social da qual faço parte, afinal, nada mais é do que um mero detalhe secundário.

Ou seja, a evolução tecnológica permite que a vida íntima das pessoas seja devastada (algumas vezes com o consentimento delas), abrindo espaço para que indivíduos maldosos possam estar onipresentes, por meio da internet e demais meios de comunicação.

Assente ao exposto é a doutrinadora Ferreira (2011, p. 611). Veja-se:

A vida moderna e a cada vez mais ameaçada necessidade de proteção de segurança pessoal e patrimonial, ameaçam o segredo da vida privada, na medida em que aparelhos de alta tecnologia registram sons e imagens não perceptíveis aos sentidos do homem.

Cabe ainda, ressaltar o papel do amplo sistema de informações computadorizadas, que podem propiciar uma devassa na vida da pessoa, na medida em que, utilizando a interconexão de fichários, formam um grande banco de dados que desvendam particularidades de sua vida, sem sua autoriza- 
ção ou conhecimento.

Errôneo seria mencionar que somente a tecnologia é a responsável por todos os malfeitos que surgiram, já que o homem é também responsável pelas escolhas que faz na sua forma de viver. A busca por uma satisfação pessoal decorrente de um exibicionismo nas redes sociais motiva algumas dessas escolhas.

Desconcertante é saber que para suprir tais tensões, as pessoas "[...] sentem-se compelidas a renunciar à própria intimidade" (COSTA JÚNIOR, 2004, p. 20), para nada mais, nada a menos, do que se sentirem reconhecidas e importantes. Ou seja, jogam-se às garras dos lobos, sofrendo diária espionagem e controle em busca da aparente satisfação pessoal. Bem aduz Gonçalves (2011, p. 336):

Com a exposição permanente se possibilita a indivíduos com idoneidade moral duvidosa se aproveitarem desses dados para seu bel prazer. Se os utilizar como curioso já não será agradável, mas é menos prejudicial do que planejar um assalto, ou um sequestro.

Por lógico que o exibicionismo que se alastrou pelas redes sociais, em congruência com o crescimento das descobertas tecnológicas e a facilidade na mantença de relação interpessoal, gera problemas a serem dirimidos pelo poder judiciário, tal qual pelo poder legislativo.

\section{STALKING}

Atualmente as atividades criminosas se dissipam fielmente, sendo as políticas públicas de combate a elas insuficientes em sua eficácia. A tecnologia, apontada no capítulo anterior é coronária de meio efetivador na execução de crimes, os quais não buscam atingir somente a integridade física ou patrimônio das vítimas, mas também seu viés emocional e psicológico.

$\mathrm{O}$ direito penal tipificador busca repreender atos e ações 
que já existem e se perpetuam há muito tempo na sociedade. Este combate à criminalidade, com caráter urgente e repressor quando tardio, muitas vezes resta fracassado.

\subsection{Conceito de stalking}

Em matéria de tipificação penal estamos ultrapassados, face aos fenômenos que ocorrem constantemente. Porém, são desconsiderados pelo universo jurídico, cujo conhecimento é importante para evitar as práticas destes comportamentos errôneos.

Sendo assim, o novo Código Penal que tramita sob forma de Projeto de Lei do Senado $n^{\circ}$ 236, de 2012, traz inovações, e uma delas é a criminalização do stalking..

Brevemente, cita-se Caetano (2015):

Numa análise histórica do termo "stalking", o fenômeno da perseguição excessiva ganhou atenção da mídia apenas há aproximadamente 15 anos, devido a alguns casos de assédio a famosos e outras celebridades no exterior. Psicólogos e psiquiatras, porém, conhecem essa ameaça há mais tempo: no século XIX, vários já escreveram sobre mulheres com fixação obsessiva que viajavam atrás de atores que idolatravam.

Ocorre que nos anos 80 , aerotomania - também chamada síndrome de Clérambault - foi classificada como distúrbio psíquico. Quem sofre dessa patologia parte do princípio irremovível de que é amado pela outra pessoa - mesmo que não haja nenhum motivo para que chegue a essa conclusão. $\mathrm{O}$ esforço incessante de entrar em contato com alguém é considerado uma das principais características da erotomania. Crime grave que por vezes é ignorado pela autoridade policial.

Stalking é uma palavra inglesa derivada do verbo tostalk cujo significado é: a perseguir (GOMES, 2012). A prática deste se consubstancia em ações de perseguição, intimidação e ameaças, em que o autor busca aproximação com sua vítima por diversas motivações (amor, ciúmes, idolatria, ódio, inveja etc), atentan- 
do contra sua integridade, predominantemente psicológica, mas também física, e vida, intimidade e privacidade. A forma mais usual e prática de perseguição se dá por meio das redes sociais e telefone, mas nada impede que seja também pessoalmente, por exemplo, vigiando a casa de seu alvo ou o seguindo.

Assentes com o acima exposto, estabelecem Rosa e Quaresma (2013):

O conceito de stalk decorre da perseguição silenciosa e despercebida, podendo-se incluir, também, a intenção de mata ou capturar, sendo mais utilizada, originalmente, em relação a animais. Ganhou, por similitude, o sentido empregado em face das perseguições pessoais, pelo qual, até mesmo por computador, se dá a perseguição reiterada e muitas vezes anônima de determinados sujeitos.

Portanto, a palavra stalking representa a existência de um perseguidor com comportamento obsessivo direcionado a alguém, cuja conduta inclui a busca por informações inerentes à vida da vítima, controlando-a. Destacam-se como núcleos essenciais desta conduta: “a) repetição; b) por curto período de tempo; c) dano físico e/ou psicológico na vítima (quer pessoal, como para sua família ou próximos, inclusive animais); d) deve ser plausível; e) capaz de impedir a realização de atividades cotidianas." (ROSA; QUARESMA, 2013).

Acerca das características, elucida Veiga (2007):

Stalking, portanto, é uma forma de violência na qual o sujeito ativo invade a esfera de privacidade da vítima, repetindo incessantemente a mesma ação por maneiras e atos variados, empregando táticas e meios diversos como, ligações nos telefones celular, residencial ou comercial, mensagens amorosas, telegramas, ramalhetes de flores, presentes não solicitados, assinaturas de revistas indesejáveis, recados em faixas afixadas nas proximidades da residência da vítima, permanência na saída da escola ou do trabalho, espera de sua passagem por determinado lugar, frequência no mesmo local de lazer, em supermercados, entre outras. 
Percebe-se que a perseguição pode se dar das mais variadas maneiras, todas elas impossibilitando que a vítima siga normalmente com sua vida. Com a intenção de adquirir poder psicológico e controlar seus movimentos, "O stalker, às vezes, espalha boatos sobre a conduta profissional ou moral da vítima, divulgando as mais variadas infâmias" (VEIGA, 2007).

Correta observação de Jorge (2015): "Cometer stalking é instigar o medo, destruir vidas e criar incertezas podendo este comportamento muitas vezes envolver grave violência e até morte."

Atualmente essa prática se tornou um fenômeno mundial, tendo em vista que é corriqueira, danosa, e pode estar ligada diretamente com a internet e outros meios de comunicação (cyberstalking), os quais, hoje, a maioria das pessoas têm acesso.

Nas palavras de Crespo (2015):

$O$ cyberstalking é, portanto, o uso da tecnologia para perseguir alguém e se diferencia da perseguição "offline" (ou mero stalking) justamente no que tange o modus operandi, que engloba o uso de equipamentos tecnológicos e o ambiente digital. Além disso, o stalking e o cyberstalking podem se mesclar, havendo as duas formas concomitantemente. O stalker -indivíduo que pratica a perseguição - mostra-se onipresente na vida da sua vítima, dando demonstrações de que exerce controle sobre ela, muitas vezes não se limitando a persegui-la, mas também proferindo ameaças e buscando ofendê-la ou humilhá-la perante outras pessoas. Curiosamente o $m$ é cometido, muitas vezes, não por absolutos desconhecidos, mas por pessoas conhecidas, não raro por ex-parceiros como namorados, ex-cônjuge, etc.

Ou seja, o cyberstalking é uma modalidade de stalking cujo perseguidor utiliza a tecnologia, por meio da internet e outros meios de comunicação, para se aproximar da vítima, importunando-a psicologicamente e até mesmo fisicamente.

Porquanto, pode-se afirmar que a prática do stalking, ainda 
que na sua modalidade cyberstalking, constitui-se aterrorizante, podendo trazer graves e irreparáveis consequências para as vítimas destes.

Imprescindível para caracterizar a prática do stalking ou cyberstalking é a violação não autorizada da vida privada da vítima, isto é, a perseguição desmedida, inoportuna, realizada contra a vontade e danosa à pessoa perseguida.

\subsection{Stalking e a violação ao direito fundamental à vida privada}

A prática do stalking indubitavelmente viola o direito fundamental à vida privada.

Isso porque, ao empregar a perseguição, o agente invade a privacidade da vítima. Esta passa a ser observada e reparada em todas as suas atividades diárias, ou na maioria delas, não tendo quaisquer liberdades de escolha por uma vivência privada, tranquila e acalentadora.

Importante mencionar que esse quadro abarrotado de perseguição ganha mais liberdade e força para acontecer com os avanços tecnológicos, visto que o agente dispõe tranquilamente das redes sociais, por exemplo, para importunar, vigiar e ficar muito próximo à sua vítima.

Mesmo que atualmente as pessoas exponham sua vida privada nas redes sociais, ainda têm o direito de tê-las preservadas, consentindo somente aquele conteúdo publicado. Ocorre que o stalking infringe esse consentimento tácito, extrapolando-o.

Um exemplo é o caso dos artistas, que fazem da veiculação de suas vidas um importante mecanismo de reconhecimento do trabalho que desempenham. Ocorre que estes escolhem, de acordo com seu íntimo, o que veiculam nas redes sociais. Porém, existe a prática da perseguição, na qual um fã monitora fielmente o conteúdo das publicações, postando mensagens, inicial- 
mente, de idolatria. $\mathrm{O}$ consequente ignorar da vítima provoca outras mensagens, agora pejorativas, cujo conteúdo ameaça-lhe a integridade psicológica ou física. Por vezes o agente até cria histórias e as veicula nas redes sociais, principalmente entrelaçadas à infidelidade e adultério.

De igual forma aponta-se a situação em que um indivíduo ameaça sua ex-companheira. Do caso narrado abaixo evidencia-se, sem qualquer dúvida, que a vítima teve sua vida privada violada, tendo em vista que o réu monitorava seu dia a dia e escrevia e-mails e mensagens para materializar as ameaças, causando transtornos psicológicos nesta. Sem contar que a vítima recebia constantemente ligações indesejadas, tendo que mudar seu número de telefone.

É a narrativa dos fatos:

FATO 01: No dia 10 de janeiro de 2013, por volta das 19h, a vítima encontrava-se no "Café Paris", situado à Rua Koesa, n. 127, Kobrasol, nesta Comarca, quando o denunciado lhe abordou e a segurou com força pelo braço desejando levá-la para rua para conversar, tendo a vítima se negado a sair do local. Ante a recusa da vítima, o denunciado prometeu-lhe causar-lhe mal injusto e grave, dizendo que iria "machucar as pessoas que ama, que ela iria sofrer as consequências", tendo deixado o local, apenas após a intervenção dos agentes de segurança do estabelecimento. À sequência, o denunciado aguardou a vítima deixar o local e passou a persegui-la desferindo sinais de luz alta com o intuito de ameaçá-la, inclusive dentro do estacionamento do Shopping Itaguaçu, sito nesta Comarca. (crime de ameaça). FATO 02: No dia 19/01/2013, por volta das $23 \mathrm{~h} 30 \mathrm{~m}$, o denunciado proferiu ameaças ao atual namorado da mesma e também a uma amiga, além de prometer causar mal injusto e grave à vítima dizendo que mandaria alguém lhe espancar na frente dos filhos. (crime de ameaça). FATO 03: Não fossem os fatos até então praticados, no dia 21/01/2013, por volta das $15 \mathrm{~h} 30 \mathrm{~m}$, o denunciado se deslocou ao local de trabalho da vítima, sito à Rua Waldemar Ouriques, 443, 
Capoeiras, Florianópolis/SC, ocasião em que ao lhe encontrar, com a intenção de perturbar a tranquilidade da vítima, disse que lhe faria passar vergonha no dia de sua formatura, a qual se aproximava. (perturbação da tranquilidade). FATO 04: Não fora isso, o denunciado, em diversas ocasiões, passou a enviar, por acinte, inúmeros e-mails à vítima, através do endereço eletrônico chacordeiro@hotmail. com, novamente perturbando-lhe a tranquilidade. Como tal, o primeiro e-mail enviado foi no dia 10/01/2013, às $14 \mathrm{~h} 23 \mathrm{~m}$, onde o denunciado lhe disse "não adianta mudar número de celular, vais mudar de emprego- Vais mudar de endereço- Vais mudar de cidade, vou te achar, eh fácil fácil. Vai ser pior pra vc, não quero machucar ninguem que vc gosta só quero conversar com ve só isso 5 min nada mais, caso contrario já sabes".

Do mesmo modo, no dia 11/01/2013, entre a $1 \mathrm{~h} 04 \mathrm{~m}$ e 9h43m, o denunciado enviou outras correspondências eletrônicas à vítima, dizendo "ta vendo fiminha e trazendo neh amanhã eu vou atrás de vc ou conversa comigo ou to no teu pé vou caçar teu namorado esse find não passa não adianta compra iphone e mudar o numero to no teu pe"; "mentiu pra mim que ia na inauguração da loja sozinha foi com o merdaoahhhh mais eu perdi essa oportunidade não darei outra chance a próxima eu pego vcs de jeito vai pro laço esse find não escapa eu juro esse find eu pego para de mentir pra mim vou acabar com a vida dele"; "Bom dia!!! Sexta sua linda até que fim você chegou... :)" essa vai ser a pior sexta feira da sua vida me desbloqueia agora e vamos conversar não vou nem trabalhar hj quero fazer plantão". Ainda, no dia 13/01/2013, às $13 \mathrm{~h} 43 \mathrm{~m}$, o denunciado encaminhou novo e-mail à vítima, dizendo "o medo de levar uma surra foi tao grande que fugiram pra uma pousada kakakkakakak uma hora eu cruzo relaxa vingança prato que se come frio". Agindo dessa maneira, o denunciado ofendeu a integridade psíquica de sua ex-companheira, subjugando-a em razão do gênero feminino, bem como em face da relação de intimidade que mantiveram, estando ele sujeito aos rigores da Lei $\mathrm{n}^{\circ} 11.340 / 06$. [sic] (SANTA CATARINA,2015).

Embora haja perturbação à tranquilidade, os fatos narrados 
se constituem muito mais severos e similares ao stalking, visto que violaram à vida privada da vítima, ameaçando-lhes a integridade física e psicológica.

Nesse sentido, o desrespeito à vida privada da vítima com os consequentes males psicológicos e físicos causados a esta, constituem-se, fielmente, na prática do stalking.

Repelir a intromissão de estranhos na vida privada do ser humano é um direito fundamental deste, que deve ser guarnecido, impedindo afrontas desrespeitosas. Portanto, o acesso a informações sobre a privacidade da pessoa e as informações sobre ela divulgadas deve ser consentido, ainda que tacitamente.

Assim, passa-se a análise da criminalização do stalking, medida que, a priori, parece cabível para a tutela, também, do direito fundamental à vida privada.

\subsection{Criminalização do stalking}

Muitos países tipificaram em seus diplomas legais a prática do stalking, iniciando, conforme aduz a história, pelos Estados Unidos. Seguiram o mesmo caminho países como Canadá, Austrália e Reino Unido, aderindo também a práticas antistalkingpor meioda legislação, assim como Áustria, Alemanha e Itália (COQUIM, 2015, p. 29).

Sobre o tema, assevera Brant (2013):

O termo stalking começou a ser usado no final da década de 1980 para descrever a perseguição insistente a celebridades pelos seus fãs. Em 1990, nos Estados Unidos, inicialmente na Califórnia, a conduta foi criminalizada. Atualmente, vários países criminalizam esse tipo de conduta inoportuna. Altas são as estatísticas da ocorrência de stalking nos países desenvolvidos. Anualmente, na Inglaterra, cerca de 600 mil homens e 250 mil mulheres são vitimados.

No Brasil, o tipo penal que mais se aproxima de uma ação de perseguidor é apenas criminalizada como contravenção 
penal, constante no art. 65 da Lei de Contravenções Penais, sob a denominação de perturbação a tranquilidade. Veja-se: "Molestar alguém ou perturbar-lhe a tranquilidade, por acinte ou por motivo reprovável: Pena - prisão simples, de quinze dias a dois meses, ou multa, de duzentos mil réis a dois contos de réis." (BRASIL, 1941).

Vale dizer que, caso a perseguição seja em desfavor de mulher, pode-se aplicar as medidas protetivas, respeitando-se a Lei Maria da Pena (Lei n ${ }^{\circ}$ 11.340/2006).

A prática acontece. Muitas são as contravenções penais de perturbação a tranquilidade, maquiadas, que em sua essência configuram stalking. Isso porque o agente ativo da contravenção, muitas vezes azucrinado pelo instinto perturbador, excede-se em sua conduta, praticando crime subsequente, como por exemplo: calúnia, injúria, difamação, ameaça, constrangimento ilegal, lesões corporais e, nos casos mais graves, estupro e homicídio.

Situações como a citada são corriqueiras, principalmente quando se trata de questões envolvendo relacionamentos amorosos. O perseguidor, insatisfeito ou descontente com alguma ação da vítima, passa a importuna-lhe à vida. Porém, nada impede que o agressor seja desconhecido, como aquele que objetiva importunar uma pessoa pública (atriz, ator, políticos), sendo seu fã, ou até mesmo pedófilos ou criminosos sexuais.

Pode-se dizer, dessa forma, que o stalking é o excesso de perturbação a tranquilidade, constituindo-se conduta mais gravosa e merecedora de criminalização, como propõe o Projeto de Lei do Senado n 236 de 2012 (Novo Código Penal).

A ausência de amparo ao tema pela legislação brasileira configura uma lacuna que precisa ser preenchida com brevidade. A perseguição constante invade a vida privada das vítimas, trazendo-lhes graves danos psicológicos e até mesmo físicos, 
bem como restringe suas liberdades de locomoção e ação, face ao domínio exercido pelo perseguidor.

Consoante a proposta da Comissão de Reforma do Novo Código Penal, o stalking é criminalizado, tendo a denominação de perseguição obsessiva ou insidiosa, com o conseguinte texto legal:

Ameaça

Art. 147 - Ameaçar alguém, por palavra, escrito ou gesto, ou qualquer outro meio simbólico, de causar-lhe mal injusto e grave:

Pena de prisão de seis meses a dois anos.

Perseguição Obsessiva ou Insidiosa

$\$ 1^{\circ}$. Perseguir alguém, de forma reiterada ou continuada, ameaçando-lhe a integridade fisica ou psicológica, restringindo-lhe a capacidade de locomoção ou, de qualquer forma, invadindo ou perturbando sua esfera de liberdade ou privacidade.

Pena — Prisão, de dois a seis anos, e multa (BRASIL, 2012).

Observa-se que a proposta apresentada tipifica o stalking como crime, sendo uma subespécie do tipo penal de ameaça, podendo ser sujeitos ativos e passivos, homens ou mulheres, sendo os bens jurídicos tutelados à liberdade e à privacidade da vítima.

A ação, entretanto, será pública condicionada, ou seja, sujeita a representação do ofendido.

Cumpre mencionar que para a configuração do delito supracitado, o agente deve ter condutas que evidenciam um contexto de perseguição, como por exemplo: ligações, e-mails, mensagens nas redes sociais e celular, reiteradas; espera na saída do local de trabalho da vítima, ou de sua casa; convites insistentes; encontros provocados; tudo isto para importunar, constranger e atingir psicologicamente e/ou fisicamente a vítima.

Isso implica, obviamente, na não concordância da víti- 
ma com os atos de perseguição do indivíduo. Não se espera punir como perseguidor o romântico que tenta desesperadamente conquistar o amor de alguém, enviando flores, cartas ou presentes. Espera-se pela tipificação da conduta obsessiva, agressiva, perturbadora, intimidadora, que limita a vítima na realização das suas atividades normais do cotidiano, portanto, havendo lesão significativa aos bens jurídicos "liberdade e privacidade" que exigem uma atuação do direito penal.

É claro que não se pode deixar de considerar, sempre, o Princípio da Intervenção Mínima, o que, nas palavras de Zaffaroni e Pierangeli (2015, p. 74), representa a "limitação da intervenção punitiva e redução da irracionalidade (ou violência) da mesma" pelo Estado. Em outras palavras, significa que a atuação do direito penal e, portanto, a aplicação de pena, deve limitar-se aos casos que não podem ser tutelados por outras esferas do direito. Entra em cena, assim, o 'princípio da subsidiariedade', segundo o qual o Direito penal deve ser a ultima ratio, o último recurso a ser utilizado, na falta de outros meios menos lesivos pertencentes a outras esferas do direito.

No caso do stalking, a conduta praticada pelo perseguidor se mostra tão grave a ponto de limitar a liberdade e privacidade da vítima, que exclui a possibilidade de outra área do direito tutelá-la, na medida de inibir satisfatoriamente a sua prática.

Porquanto, demonstrou-se que a criminalização do stalking resta imprescindível para que os atos advindos da perseguição continuada ou reiterada que se configuram obsessiva ou insidiosa, possam ser repreendidos adequadamente, não sendo, como atualmente, punidos com contravenção penal ou crimes colaterais de menor potencialidade lesiva.

\section{CONCLUSÃO}

Verificou-se que o direito fundamental à vida privada foi 
tutelado no ordenamento jurídico brasileiro pela Constituição da República Federativa do Brasil de 1988. E mais, evidenciou-se quão importante é o referido direito fundamental, ao passo que este diz respeito aos elementos que formam a vida de uma pessoa, e que, portanto, não são de conhecimento público. Dai surge tal magnitude, tendo em vista que à vida privada se configura como ícone formador da personalidade humana.

Ocorre que, a partir da Revolução Industrial surgiram novos avanços tecnológicos que, com o passar dos tempos, mudaram a forma do ser humano se relacionar, tal qual, pela internet e eletroeletrônicos. Dessa forma, fez com que à vida privada sofresse violações temerárias. Isso porque são ínfimas as pessoas que não possuem contas em redes sociais, ou que não se comunicam através de aparelhos celulares, ficando cada vez mais expostas a vida externa.

Aqui merece holofote a prática do stalking, considerando que são muito mais fáceis de execução os meios de perseguição, pois existe a internet e os celulares. É cediço que as pessoas postam mensagens demonstrando suas vidas nas redes sociais, consentindo tacitamente algumas informações; e mais, há facilidade de comunicação por mensagens de texto, as quais chegam à vítima com rapidez.

Ora, o perseguidor consegue, de forma reiterada ou continuada, ameaçar a integridade física ou psicológica da vítima, invadindo sua privacidade, ao passo que ultrapassa as barreiras de consentimento das informações dadas pela vítima. É, portanto, uma forma de violência psicológica e social, passível, dessa forma, de penalização.

É de conhecimento que o Código Penal Brasileiro de 1941 não se encontra preparado para enfrentar as questões advindas pela era tecnológica, sendo necessárias adequações legais.

Porquanto, o saltking não é crime no Brasil. Denota uma 
contravenção penal nominada de perturbação à tranquilidade, que resta em penalização ínfima, e por ser assim, resulta em uma aglomeração de tipificações penais com intuito de se chegar a uma penalização razoável. Porém, esta modalidade de perseguição é de maior seriedade do que os outros delitos parcelares.

Dessa forma, a aprovação do Novo Código Penal, com a inserção do crime de perseguição obsessiva ou insidiosa, como submodalidade do crime de ameaça, resta imprescindível para a tutela, também, do direito fundamental à vida privada, além da liberdade da vítima. A conduta que o Projeto do Novo Código Penal visa criminalizar representa uma conduta grave que persegue, importuna, agride, amedronta, intimida a vítima, exigindo a tutela penal.

\section{REFERÊNCIAS}

ARDENGHI, Régis Schneider. Direito à vida privada e direito à informação: colisão de direitos fundamentais. Revista da ESMESC, Florianópolis, v. 19, n. 25, p. 227-251, 2012.

BRANT, Marcos Henrique Caldeira. Stalking-perseguição obsessiva. Belo Horizonte, 2013. Disponível em: $<$ http://www.tjmg.jus.br/portal/imprensa/artigos/detalhe-5.htm\#. VsNsfUBwrBt>. Acesso em: 16 fev. 2016.

BRASIL. Constituição (1988).Constituição da República Federativa do Brasil. Brasília, DF: Senado Federal, 1988. Disponível em: <http://www.planalto.gov.br/ccivil_03/ Constituicao/Constituicao.htm>. Acesso em:16 fev. 2016.

BRASIL. Decreto-Lei n ${ }^{\circ} 3.688$, de 3 de outubro de 1941.Lei das contravenções penais. Disponível em: <http://www.planalto.gov.br/ccivil_03/Decreto-Lei/Del3688.htm>. Acesso em: 16 fev. 2016.

BRASIL. Projeto de lei do Senado Federal no 236 de 2012 (Novo Código Penal). Disponível em: <http://www.senado.leg.br/atividade/rotinas/materia/getPDF.asp?$\mathrm{t}=111516 \& \mathrm{tp}=1>$. Acesso em: 22 fev. 2016.

BULOS, UadiLammêgo. Constituição Federal anotada. 10. ed. rev. atual. e reformulada até a Emenda Constitucional n. 70/2012. São Paulo: Saraiva, 2012.

CAETANO, Eduardo Paixão. Perseguição obsessiva que ofende os valores de direitos humanos, o crime de stalking.Conteúdo Jurídico, 2015. Disponível em: $<\mathrm{http}: / /$ www.conteudojuridico.com.br/?colunas\&colunista=57211_\&ver=2128>. Acesso em: 16 fev. 2016.

CRESPO, Marcelo. Algumas reflexões sobre o cyberstalking.Disponível em: <http:// 
canalcienciascriminais.com.br/artigo/algumas-reflexoes-sobre-o-cyberstalking/>. Acesso em: 16 fev. 2016.

COSTA JÚNIOR, Paulo José da. O direito de estar só:tutela penal da intimidade. 3 ed. São Paulo: Siciliano Jurídico, 2004.

COQUIM, Ana Isabel Anastácio. Stalking-Uma realidade a criminalizar em Portugal? 2015. 74 f. Dissertação (mestrado)- Faculdade de Direito da Universidade de Coimbra, Portugal. Disponível em: < https://estudogeral.sib.uc.pt/bitstream/10316/30073/1/Stalking.pdf $>$. Acesso em: 19 fev. 2016.

DECLARAÇÃO AMERICANA DOS DIREITOS E DEVERES DO HOMEM, Nona Conferência Internacional Americana, Bogotá, 1948. Disponível em <http://www.cidh. oas.org/Basicos/Portugues/b.Declaracao_Americana.htm>. Acesso em: 16 fev. 2016.

DECLARAÇÃO UNIVERSAL DOS DIREITOS HUMANOS, ONU, 1948. Disponível em: <http://www.mp.go.gov.br/portalweb/hp/7/docs/declaracao_universal_dos_direitos_do_homem.pdf>. Acesso em: 16 fev. 2016.

FERNANDES, Bernardo Gonçalves. Curso de direito constitucional. 7. ed. Bahia: Editora JusPodivim, 2015.

FERRARI, Regina Maria Macedo Nery. Direito constitucional. São Paulo: Editora Revista dos Tribunais, 2011.

FERREIRA FILHO, Manoel Gonçalves. Aspectos do direito constitucional contemporâneo. 3. ed. São Paulo: Saraiva, 2011.

GOMES, Luiz Flávio. Perseguição obsessiva pode se tornar novo tipo penal. Disponível em: <http://www.conjur.com.br/2012-jun-04/perseguicao-obsessiva-chamada-stalking-tornar-tipo-penal>. Acesso em: 16 fev. 2016.

GONÇALVES, Antonio Baptista. Intimidade, vida privada, honra e imagem ante as redes sociais e a relação com a internet. Limites constitucionais e processuais. Revista de direito privado, São Paulo, v. 48, n. 12, 2011.

JORGE, Julia Quaresma Passos. O stalking e a legislação penal brasileira. Empório do Direito, 2015. Disponível em < http://emporiododireito.com.br/o-stalking-e-a-legislacao-penal-brasileira/>. Acesso em: 16 fev. 2016.

MENDES, Gilmar Ferreira; COELHO, Inocêncio Mártires;BRANCO, Paulo Gustavo Gonet. Curso de direito constitucional.5.ed. rev e atual. São Paulo: Saraiva, 2010.

MOREIRA, Rodrigo Pereira. Autonomia existencial da vida privada na internet:os cookies, o spamming e as redes sociais. Disponível em: <http://www.publicadireito. com.br/artigos/?cod=fde9264cf376fffe >. Acesso em: 16 fev 2016.

OLIVEIRA, James Eduardo. Constituição Federal anotada e comentada: doutrina e jurisprudência. Rio de Janeiro: Forense, 2013.

ROSA, Alexandre Morais da; QUARESMA, Heloisa Helena. Stalking e a criminalização do cotidiano:Hollywood é o sucesso! Disponível em: < http://heloisaquaresma. blogspot.com.br/2013/02/stalking-e-criminalizacao-do-cotidiano.html $>$. Acesso em: 22 fev. 2016.

SANTA CATARINA. Tribunal de Justiça do Estado de Santa Catarina. Acórdão no Agravo de Instrumento n. 2004.030671-5, de Joinville, rel. Des. Marcus Tulio 
Sartorato, j. 11-02-2005. Disponível em: <http://app6.tjsc.jus.br/cposg/pcpoSelecaoProcesso2Grau.jsp?cbPesquisa=NUMPROC\&Pesquisar=Pesquisar\&dePesqui$\mathrm{sa}=20040306715>$. Acesso em: 22 fev. 2016.

SANTA CATARINA. Tribunal de Justiça do Estado de Santa Catarina. Apelação Criminal n. 2015.066045-5, de São José, Relator: Des. Moacyr de Moraes Lima Filho. Florianópolis, SC, 15 de dezembro de 2015. Disponível em: <http://app6.tjsc.jus.br/ $\mathrm{cposg} /$ servlet/ServletArquivo?cdProcesso $=01000 \mathrm{VTPZ} 0000 \&$ nuSeqProcessoM$\mathrm{v}=$ null\&tipoDocumento $=$ D\&cdAcordaoDoc $=$ null\&nuDocumento $=8771953 \& \mathrm{pdf}=-$ true>. Acesso em: 16 fev. 2016.

SANTA CATARINA. Tribunal de Justiça do Estado de Santa Catarina. Apelação Criminal n. 2015.045476-6, de Itapiranga, rel. Des. Rodrigo Collaço. Florianópolis, SC, 27 de agosto de 2015. Disponível em:< http://app6.tjsc.jus.br/cposg/servlet/ServletArquivo? cdProcesso=01000V5BS0000\&nuSeqProcessoMv=null\&tipoDocumento=D\&cdAcordaoDoc $=$ null\&nuDocumento=8394256\&pdf=true $>$. Acesso em: fev. 2016.

VEIGA, Ademir Jesus da. O crime de perseguição insidiosa (stalking) e a ausência da legislação brasileira. Disponível em: $<$ http://veiga.blogs.unipar.br/?p=3>. Acesso em: 16 fev. 2016.

ZAFFARONI, Eugenio Raul; PIERANGELI, José Henrique. Manual de direito penal brasileiro-Parte Geral. 11. ed. 2015. v. 1.

Artigo recebido em 30/05/2016

Artigo aprovado em 13/07/2016 